LEITURA - LITERATURA E UTOPIA, n. 32, p. 83-97, jul./dez. 2003.

\title{
BARROCAS UTOPIAS (DESTI-NAÇÃO AO NÃO LUGAR)
}

\section{Carlos Mascarenhas*}

Resumo: Neste artigo, estamos refletindo como o olhar barroco se coaduna com uma mirada utópica, a partir de pensamentos lançados no contexto literário da América Latina.

Palavras-chave: Barroco. Utopia. Identidade e Diferença. Cultura e Razão Civilizadas. Literatura Latino-Americana.

A reta da Europa curva-se ante o Brasil.

Paulo Leminski, Catatau.

No presente artigo, pretendemos refletir em torno de uma possível pertinência existente entre os olhares do barroco e da utopia, no contexto do pensamento literário da América Latina. E o que nos convoca a tentar esse percurso reflexivo justifica-se, na medida em que notamos a recorrência da dicção barroca na produção literária de autores, não só do momento histórico específico em que esse estilo se concretizou nos tempos coloniais, mas, sobretudo, porque ele tem curiosamente permanecido entre nós, por vezes, de forma indireta e, por outras, muito explicitamente, como no caso de sua re-aparição, renomeada sob a égide do Neo-Barroco.

Desde os momentos iniciais, nos primeiros contatos com esse "outro" e Novo Mundo, que veio a ser designado pelo nome de América, houve por parte do macho branco europeu um movimento de projeção de ideais e fantasias, donde se visava encontrar, aqui, o lugar destinado a promover o reinício daquela civilização, já profundamente marcada pelos equívocos de um velho mundo. A feição utópica de tal empreendimento elegeu como alicerce a imagem do solo original da Terra virgem, lugar de purificação dos antigos

* Doutorando em Teoria da Literatura pela Universidade Federal de Pernambuco. 
vícios urbanos. Daí, a América ser vista, desde o início, como o território da utopia, como lugar votado às frutificações do futuro... Todavia, ao se tornar o espaço de implantação do projeto europeu de reforma social, logo emergiu a questão do saber "como" caracterizar esse "outro", ocupante natural do Novo Mundo. Francisco Moraes Paz observa que

o problema que se coloca aos europeus é fazer com que os povos distantes situem-se em seus esquemas analíticos, introjetando sua lógica. Pela Enciclopédie, os povos não civilizados dividem-se em selvagens e bárbaros. Os selvagens formam pequenas naçōes dispersas; os bárbaros conhecem a unidade através de um chefe militar e/ou religioso. O esquema trinário selvagem-bárbaro-civilizado funda um princípio interpretativo global com pretensões de dar conta da evolução das diferentes sociedades e de destacar o momento que passam a fazer parte da história. Por certo que este momento confunde-se com o encontro do bárbaro com o civilizado. No entanto, resta saber quem é bárbaro. [...] A fúria dos cristãos, combinando os interesses religiosos aos econômicos, não expressa qualquer traço de civilidade (1996, p. 29).

Esse esquema interpretativo empregado pela Europa sobre o Novo Mundo, por ser fortemente preso à sua própria auto-referência econômico-científica e, sobretudo, religiosa -, não tardou muito a transformar as antigas fantasias de um suposto paraíso terrestre em imagens opostas, onde o encanto inicial se desvanece sob a frustração diante da diferença dos modos dos nativos. Nesse ínterim, podemos perceber o movimento de inversão em torno de uma fantasia escatológica, passando da crença no Paraíso Terrestre à visão de um mundo infernal repleto de maus hábitos e pecados.

Recorramos, mais uma vez, a Francisco Moraes Paz, a fim de reforçar a nossa percepção sobre as dificuldades emergidas nesse contexto:

Em debates dessa natureza revelam-se as divergências dos europeus sobre as formas de se relacionar com as culturas encontradas desde as grandes navegações do século XVI. O reconhecimento dos direitos dos outros 
povos versus os interesses coloniais representam uma faceta da questão. Ao seu lado está a visão européia de berço da moderna civilização e a dificuldade em conviver com culturas que revelem lógica social, econômica ou religiosa diversa. Em suma, conviver com realidades que evidenciam os limites ou os medos do homem renascentista. A ampliação das fronteiras geográficas européias, como destaca Jean Delumeau, comprovara a extensão dos domínios de satã. No imaginário católico, derrotado por Cristo, o demônio fora expulso do Ocidente. No Oriente, a ação dos missionários faz frente à situação. Na América, entretanto, reina absoluto.

A idolatria e o canibalismo dos nativos comprova a maléfica influência. A ação cristã colonizadora busca, pois, a conversão e a salvação desses povos - bem como dos negros e colonos. Sim, porque os Trópicos são o último reduto do demônio, todos estão sujeitos ao pecado (1996, p. 25).

Um encontro, pois, que se perfaz nesses termos talvez aponte aí para uma das raízes do que testemunhamos como a incessante produção de equívocos durante um processo de civilização, quando um dos termos da relação coloca-se numa posição de superioridade, detendo as verdades e certezas sobre a direção e o sentido da vida e do mundo. Com a reversão do signo escatológico, que tinha por escopo inicial a renovação do mundo cristão no "paraíso terrestre", muitas teorias filosóficas surgiram para tentar dar conta do Novo Mundo e reforçar o projeto da missão civilizatória européia. Nesse debate de exterminação do mal, que da Contra-reforma cristã passou para os tempos iluministas - em que se esperava suplantar as imperfeições do homem mediante as Luzes da Razão - houve, também, o posicionamento de vozes que, de forma singular, questionavam e relativizavam a visão do homem europeu, assinalando, no seio hegemônico e auto-centrado do colonizador, uma forma de pensar que, por um processo de espelhamento, expressava suas divergências. Assim foi o caso de Montaigne que, segundo Francisco Moraes Paz,

Em Ensaios, depara-se com a questão do poder dos costumes, da diversidade do vivido, e conclui pela 
inexistência de uma moral absoluta. Como todo julgamento é um hábito, afirma, não há como garantir que a liberdade seja um bem e, sua ausência, um mal. O princípio universal da liberdade é somente um hábito transformado em razão universal. O que transforma o homem num cidadão do mundo, portanto universal, é a tolerância com os outros. Reconhece a qualidade dos canibais e eleva o canibalismo à realização plena do espírito guerreiro do índio. Contrapondo-se à sociedade, Montaigne lembra ser pior comer um homem vivo, despedaçado em seus tormentos, que comer um homem morto (1996, p. 39).

Esse nosso sucinto passeio historiográfico justifica-se na medida em que pudemos chegar até a visão de um pensador como Michel de Montaigne que, já naquele momento - trata-se de um filósofo do final da Renascença -, não obstante a dificuldade de se conseguir pensar além da dimensão consensual mediana em que se encontravam seus contemporâneos, encetou uma maneira de ver e pensar que, curiosamente, já sinaliza algo que veio a ser peculiar ao espírito barroco, nas manobras de raciocínios por meio de um estilo de escrita que visivelmente desestabiliza qualquer pretensão de centralidade conceitual em termos absolutos. A sensualidade fugidia das suas idéias buscava acompanhar a relatividade na efemeridade das coisas do mundo ao seu redor e de si próprio, envolto nas pequenas experiências do seu cotidiano. A glória do classicismo recaiu sobre Descartes, cujo pensamento mirava a certeza metafísica, que veio legitimar os anseios das máquinas administrativas imbuídas nos projetos de conquista, de dominação e de poder. No lugar da verdade, para Montaigne, talvez, "um saber que não se sabe", como diria Maria Rita Kehl, que tecendo comparações entre os dois, comenta:

Ora, meio século antes das Meditações de Descartes, outro filósofo, já herdeiro do desencantamento do mundo mas também de uma primeira emancipação do homem, fundada no pensamento humanista, inaugurou outra modalidade do grande exercício de constituir o ser na linguagem. Mas, à diferença de Descartes, Michel de Montaigne não fundou uma certeza metafísica baseada num suposto pensamento "puro". Foi na escrita, e na escrita dirigida a seu semelhante (recurso inventado pelo 
filósofo depois de dezessete anos de luto pela perda do grande amigo e interlocutor Étienne de la Boétie), que Montaigne teceu o fio de seu $e u$. [...] Montaigne não busca uma certeza metafísica sobre o ser. Sua certeza é humanista, e ele compartilha com seu semelhante. Não funda o $e u$ na verdade que ele enuncia, mas no diálogo propriamente dito: "A palavra é metade daquele que a diz, e metade de quem a escuta", escreveu no ensaio "Da experiência" (2002, p. 71).

E essa mesma ética relativista de Montaigne podemos sentir ecoar nas palavras de Antônio Vieira, ícone da prosa barroca na língua portuguesa que, no Brasil, ao pronunciar seu Sermão de Santo Antônio, também conhecido como Sermão aos Peixes, pregado em São Luís do Maranhão, no ano de 1654, preocupado com a situação dos índios violados e escravizados pelos colonos, usa sua retórica barroca para denunciar, através da alegoria dos peixes, a injustiça que se perpetrava ali, no seio do sistema colonial. Assim, enunciava ele aos fiéis:

A primeira coisa que me desedifica, peixes, de vós, é que vos comeis uns aos outros. Grande escândalo é este, mas a circunstância o faz ainda maior. Não só vos comeis uns aos outros, senão que os grandes comem os pequenos. Se fora pelo contrário era menos mal. Se os pequenos comeram os grandes, bastava um grande para muitos pequenos; mas como os grandes comem os pequenos, não bastam cem pequenos, nem mil, para um só grande. [...] Vós virais os olhos para o mato e para o sertão? Para cá, para cá; para a cidade é que haveis de olhar. Cuidais que só os Tapuias se comem uns aos outros, muito maior açougue é o de cá, muito mais se comem os brancos. Vede vós todo aquele bulir, vedes todo aquele andar, vedes aquele concorrer às praças e cruzar as ruas: vedes aquele subir e descer as calçadas, vedes aquele entrar e sair sem quietação nem sossego? Pois tudo aquilo é andarem buscando os homens como hão de comer, e como se hão de comer (VIEIRA, 1945, p. 264-67).

Curiosamente, parece até que a retórica barroca, com todo esse jogo de antíteses, vem espelhar perfeitamente as inversões 
ideológicas que recheavam os discursos da razão civilizada; esta procurava se manter por dicotomias de cunho exclusivista, nas quais as dimensões do outro eram lançadas ao pólo de valoração negativa. Assim figuram nos binômios como: civilizados (brancos) versus selvagens (tapuias); cidade versus mato/sertão; grandes versus pequenos; em suma, identidade versus diferença.

Mais impressionante, ainda, se pensarmos que, após todos esses séculos, o sermão acima permanece perfeitamente contemporâneo e afinado ao diapasão da lógica do consumismo globalizado.

Do signo aberto à recepção geradora: insubmissão e inacabamento

Hoje, sabemos que a formação do estado-nação - fenômeno distintivamente moderno - só foi possível a partir do momento em que dispunha de todo um arsenal propagador de significados para a fundação das identidades nacionais, culturais, étnicas e religiosas. $\mathrm{E}$ as culturas nacionais foram forjadas por símbolos e representações sustentadas pelas narrativas, estórias e memórias ancoradas em imagens construídas coletivamente. Essa é a função simbólica de qualquer discurso. Quanto a nós, latino-americanos, por que o barroco haveria de ter encontrado um certo domicílio e o que ele teria a ver com o emaranhado aparentemente indefinido do que somos?

Alfredo Cordiviola, ao comentar sua interpretação sobre uma frase de Darcy Ribeiro acerca do Memorial da América Latina - obra desenhada por Oscar Niemeyer -, enuncia:

Pois difusa, hipotética, é a entidade conhecida como América Latina, objeto elusivo e constante para um pensamento que insiste em afirmar a necessidade da sua existência. De Bolívar a Martí, de Henrique Ureña a Ángel Rama, a América Latina se perfila como um ensaio, uma tentativa, uma imposição intelectual de integração que não opera por simples acumulação de particularidades nacionais, mas que aponta para a criação de uma identidade heterogeneamente transnacional que sirva como espelho de reconhecimento de uma diferença e como um modo de pensar o devir da ordem mundial (2001, p. 6). 
O grande desafio de se pensar a nossa realidade continental, sobre o "ser americano", talvez se evidencie na observação de Irlemar Chiampi, de que "não encontramos na reflexão norte-americana, nem na brasileira, a mesma veemência, e até obsessão, com que os hispano-americanos têm sentido a necessidade de definir a sua cultura no contexto ocidental, de identificar-se diante das diversas formas de colonização, de criar um sentido e um método de conhecimento para sua realidade histórica" (1980, p. 96). Isso é o que tentamos sinalizar na peculiaridade do barroco latino-americano, na medida em que este parece se impor como uma forma de interagir com outros discursos construídos sobre nós, os quais, de longe, expressam o desejo de reconhecimento e valorização do desconhecido enquanto alteridade.

E é graças a essa "crise ontológica" que observamos uma inquietação se manifestar no pensamento de diversos autores, como uma forma, talvez, de promover a afirmação de uma entidade "hipotética e difusa", mas que também, por isso mesmo, venha a surpreender o mundo contemporâneo com uma mirada muito particular, por portar em si o traço da heterogeneidade fractalizada; ${ }^{1}$ o que já representa uma forma de inscrição de algo caracteristicamente singular que perpassa referendando o devir sócio-histórico e cultural da América Latina. Imprescindível, também, seria observar que, com a monopolização do nome América pelos norte-americanos, uma nova perda veio aguçar ainda mais esse sentimento de reivindicação do "significante original" no pensamento literário de alguns autores da parte sul da América. Segundo Irlemar Chiampi,

O deslizamento semântico iniciou-se com a usurpação do nome América pelos norte-americanos, quando em 1776 foi uma solução para as treze ex-colônias inglesas integrarem uma nação sob uma denominação abrangente. Depois, a hegemonia política e econômica dos Estados Unidos no século XIX consumou o emprego

1 A propósito da "experiência fractal" como traço característico das sociedades coloniais na América Latina, conferir o ensaio "Do Barroco ao Neobarroco. Fontes coloniais dos tempos pós-modernos”, de Serge Gruzinski, In: CHIAPPINI, Ligia, AGUIAR, Flávio Wolf (Orgs.). Literatura e história na América Latina. São Paulo: EDUSP, 2001. 
restrito do nome que durante três séculos vinha significando a porção sul do continente. As denominações objetáveis e provisórias (e politicamente intencionadas: Hispano-América, América Latina, IbéroAmérica, Indo-América) nunca puderam substituir a significação do nome original (2001, p. 97).

Esse ponto, referente à perda do "nome original", reveste-se de grande importância para o objetivo visado em nosso estudo, uma vez que parece estar precisamente aqui o motivo mais relevante à geração de tantos ensaios, teorias e ficções, no sentido de promover uma "revisão conceitual da América". É nesse aspecto onde percebemos o movimento de um trabalho utópico que, não raro, assinala o desejo de se reinventar através de uma imagem poética fundadora, capaz de suportar um possível reencontro com o "vazio original" e gerar "a construção de um ente diferenciado da Europa" (2001, p. 101).

Para o escritor cubano Lezama Lima, a América Latina expressa sua insubmissão a partir do momento em que põe em curso seu genuíno movimento interpretante e auto-fundador por uma consciência crítica em torno de si mesma. Trata-se, para ele, de um movimento voraz que se perfila na metáfora barroca de um "protoplasma incorporativo", na qual se vislumbra a atitude cultural americana, ao absorver as heranças da tradição ancestral autóctone e ibérica que resulta num "espaço gnóstico" fecundador de imagens e produtor de conhecimentos. Além dessa tese, outras tantas sustentam "a idéia da cultura americana como espaço de junção do heterogêneo, de síntese anuladora das contradições, de fusão de raças e culturas díspares" (CHIAMPI, 1980, p. 133). O que nos leva a pensar no estilo de uma cultura que se distingue, esboçando-se pela imagem de um espaço aberto à recepção geradora, onde a receptividade, antes de significar uma postura passiva e meramente dependente, implica-se no ato gerativo de produzir transformações. É o que Irlemar Chiampi observa como "o signo da abertura americana à recepção geradora, que converte o produto final não em cópia, mas em simulacro destruidor da dignidade do modelo" (1980, p. 127).

Um signo de insubmissão, portanto, que, ao invés de se fechar de forma redutora na reivindicação mítica de alguma pureza original, essencial, afirma-se justamente no lançar-se, cada vez mais, ao 
universo polifônico das misturas germinativas em que se proliferam transculturações. Nessa perspectiva, é que também identificamos o vislumbre vertiginoso de um tipo de olhar barroco votado ao desconforto do inacabamento. Todavia, longe da imagem paroxística traduzida pela idéia do impasse, esse mesmo olhar é o que não cessa de pulsar, uma disposição prospectiva que não se acomoda à condição de ser e estar como um mero laboratório da pós-modernidade, como pretenderiam alguns...

Brasil: a curva do acaso

O discurso oficial da narrativa histórica sobre a "descoberta" do Brasil já nos oferece de presente a marca do acaso. Curiosamente, essa marca esboça em si mesma a especificidade do traço barroco: a curva do desvio. A curva que "por acaso" teria acontecido na reta da rota cabralina. Não seria excessivo tomar a imagem do desvio como um detalhe eloqüiente para considerar que o Brasil já nasceu assim, desde sempre, refratário aos cálculos do universo renascentista. Essa é a idéia que aludimos na nossa epígrafe: "A reta da Europa curva-se ante o Brasil".

E Carlos Pena Filho (2000, p. 64), em seu poema "Pedro Álvares Cabral", enuncia:

O enorme céu que cobre mar e mágoas

e abriga os astros

sustém meu claro sonho sobre as águas

velas e mastros

Um dia hei de encontrar terra ignota:

é assim quem sonha.

E se nenhuma houver em minha rota

que Deus a ponha

Em meio ao longo mar não faço caso

dos dias meus,

pois tenho a guiar-me o vento ou o puro acaso

e o acaso é Deus. 
Ao longo do poema acima, assistimos à voz ficcional de Cabral, perdido pelo Atlântico, em meio à viagem que viria dar no Brasil. Nesse texto, interessa-nos observar a feição utópica que se manifesta pela voz poética. Sem mais o amparo de bússolas ou de outros instrumentos que a tecnologia marítima da época pudesse lhe oferecer como guias ao destino certo, só lhe resta mesmo apelar ao acaso para que, finalmente, chegue à terra desejada. Observamos, na circunstância de perda da certeza do caminho que se projeta na suspensão espaço-temporal do oceano, a emergência de uma utopia pelo sonho de encontrar a "terra ignota". Vemos, na errância, a perda da certeza que simultaneamente suscita o estado de despojamento e de entrega à lógica do acaso e - por que não dizer? - do próprio desejo. E o desejo de encontrar a "terra ignota", ao mesmo tempo em que aponta para algo novo e desconhecido, parece querer indicar sobretudo a dimensão incógnita de uma determinada perspectiva com relação ao seu próprio devir.

É, pois, na perspectiva incerta e indefinida desse olhar, onde situamos o desdobramento infinito e vertiginoso da fractalidade barroca, concomitantemente ao olhar utópico que se lança algures, quer dizer, na analogia entre a inquietação do olhar barroco e a condição de se destinar a um não-lugar. Importa dizer que a escolha do texto acima não se pautou pelos pressupostos estilísticos e formais que caracterizariam o barroco, obviamente, mas tão somente por ele representar a circunstância da viagem de Cabral, que resultou na "descoberta do Brasil". Todavia, do ponto de vista mesmo do universo barroco, a paisagem sócio-psíquica que lhe dá solo reflete-se na imagem crítica do homem flutuante ao sabor do acaso, marcado pelo signo da perturbação da perda. No tópico anterior deste artigo, registramos a questão da perda do nome América, na América Latina, e aqui vemos Cabral também perdido, descentrado, desterritorializado e sonhando com um porto seguro. Ademais, podemos também encarar esse texto como uma espécie de alegoria histórica, quer dizer, estamos utilizando a literatura como uma via de reflexão historiográfica.

Segundo Serge Gruzinski,

A experiência fractal marcou para sempre as culturas coloniais. De um lado, porque ela consagra a predominância da "recepção fragmentada", pois a invasão desencadeia, incansavelmente, para os dois 
campos, a perda, a dissolução das referências originais africanas, mediterrâneas, pré-hispânicas - e a elaboração de novas marcas (2001, p. 79).

A dissolução das referências originais não deixa também de suscitar, sob a marca traumática da perda, uma constelação dramática de memórias e sentimentos relativos a um tempo de violações, ruínas e sofrimentos. Entretanto, a preciosidade da citação acima reside na observação da existência, ao mesmo tempo, de um outro campo vetorizado para um devir voltado à "elaboração de novas marcas". Eis a chave do que identificamos como o nascedouro de um olhar que se constitui de maneira paradoxal entre ruínas e perdas, não obstante, afirmando-se também como possibilidade de se reinventar, nas inscrições de novas marcas.

O classicismo postulava a totalidade orgânica, numa circularidade perfeitamente acabada. O barroco vem antagonizá-lo, com suas representações turbulentas e fragmentadas, refletindo a violência da experiência histórica. Como sugeriu Walter Benjamin, o traço distintivo do barroco, "seu teor, seu verdadeiro objeto, é a vida histórica" (apud BOYLE, 1994, p. 110) e, nesse sentido, podemos vêlo como um instrumento, cuja tarefa consiste em efetuar incessantes críticas, impugnando e afirmando sua insubmissão ante toda ordem que se queira instalar hegemonicamente.

A sensibilidade contemporânea indicia muitos pontos em comum com a cultura barroca, e, entre nós, podemos nos deparar com inúmeras manifestações reatualizadoras, não apenas na literatura, como em outros campos da arte. É o que podemos demonstrar através do seguinte poema de Augusto de Campos, "Cidade/City/Cité"

ATROCADUCAPACAUSTIDUPLIELASTIFELIFEROFUGAHIST ORILOQUALUBRIMENDIMULTIPLIORGANIPERIODIPLASTIP LUBIRAPARECIPROSAGASIMPLITENAVELOVERAVIVAUNIV ORACIDADECITYCITÉ

Esse texto foi exibido em indoor eletrônico regulado por computador, na Avenida Paulista, em 1991, por ocasião do centenário da avenida. Antes, porém, ele havia sido publicado no livro Viva vaia, do mesmo autor, em 1963. 
O texto, caudaloso e labiríntico, parece metaforizar o seu objeto referencial que finalmente surge em meio ao fluxo caótico de fragmentações verbais: a cidade. E, mesmo assim, sob a máscara híbrida de um sufixo polilíngue para uma aglutinação de 28 núcleos lexicais, a cidade expande-se perifericamente como uma constelação ao mesmo tempo aberta e hermética. Tal é a estranheza de um poema que se exibe como se fosse uma única "palavra de 153 letras"!

Para Serge Gruzinski,

Os imaginários coloniais, bem como os de hoje, praticaram a descontextualização e o reemprego, a desestruturação e a reestruturação das linguagens. $O$ embaralhamento das referências, a confusão de registros étnicos e culturais, o entrecruzamento do vivido e da ficção, a difusão das drogas, as práticas do remix, são traços que aproximam sem os confundir - pois a história não se repete -, imaginários de ontem e de hoje. Todos incontestavelmente saíram do universo fractal nascido do contato dos dois mundos e perpetuam em toda América latina situação de fronteira. Caso contrário, como interpretar, com relação às grandes terras do barroco americano, o México e o Brasil, o fantástico impulso da imagem televisiva que, pela primeira vez, permite a esses países lançarem-se numa expansão conquistadora? (2001, p. 88).

"Cidade/City/Cité" parece querer não só representar mas presentificar a cidade, quando essa aparece concretizada na própria superfície material gráfica dos signos verbais, como um carrefour lingüístico, entidade que se traduz como uma espécie de encruzilhada polifônica, babel de hibridismos culturais. Escrito originalmente em uma única linha, o texto rompe concretamente os limites físicos do objeto-livro. Eis o "embaralhamento das referências" miméticas, onde o empírico e o ficcional se confundem, como se o texto fosse apenas um fragmento metonímico inserido numa cadeia constelacional de escrita muito mais ampla que é a cidade mesma, com seus letreiros de anúncios, propagandas, etc. Além das bordas do livro, o texto/poema transcende a mímesis e afirma-se como mais uma emanação do real; uma paródia, talvez, hiper-real da galáxia renascentista de Guttemberg, em plena pós-modernidade. Pois, como diria, ainda, 
Serge Gruzinski: "por ser majoritariamente uma imagem miraculosa, a imagem barroca não é a réplica de um modelo. Portanto, ela não funciona numa lógica da mímesis, sendo, antes de tudo, uma presença viva" (2001, p. 83).

Historicamente, tem sido comum o barroco surgir como resposta ética e estética aos períodos críticos em que a sociedade sinaliza suas perturbações morais e flutuações na economia. Sendo assim, não seria o texto de Augusto, também, uma crítica poéticoprofética para os nossos tempos neo-liberais, onde o "monstro verbal cidade/city/cité" tenta mostrar "uma presença viva" de uma determinada face voraz, do que veio a ser o fenômeno da globalização? O texto, sem dúvida, é intrigante, provocador e nos afeta. E o poder de afetar, através da manipulação do simbólico, é a grande razão que caracteriza o barroco.

Desde o século XVI e XVII, a estandartização da ortografia, a regulação e normatização da linguagem estiveram intrinsecamente ligadas às determinações exigidas pela administração dos Estados nacionais nascentes. O ideal de uma linguagem transparente e unívoca tornou-se a miragem ideologicamente perseguida e almejada pelo Estado centralizador, absolutista.

Embora, inicialmente o barroco tenha parecido ser uma estratégia político-estética a serviço da ideologia contra-reformista, o fato é que tudo parece indicar a existência de uma tendência refratária na própria natureza desse estilo, cuja retórica não se deixou prender, fixando-se nas diretrizes prescritas na legislação dos tratados normativos que caracterizariam a poética barroca. A extemporaneidade barroca evidencia que essa estética porta, em si, uma soltura que não se comporta como algo a serviço de uma máquina racionalizante, obcecada pelo controle do imaginário. Se é próprio do barroco serpentear, surpreendendo a sintaxe na aparente descontinuidade das suas digressões, isso exprime sua natureza artificiosa, cujo engenho parece consistir na capacidade de se despojar do que seria a verdade, a origem e/ou o fim. Eis o que faz o barroco ser trans-histórico, como diria Deleuze. Pois a lógica da racionalidade que se denota aqui é a de uma razão que - por mais arrojados e aguçados os artifícios de seu engenho estético - afirma o paradoxo de querer admitir, paralelamente, a fragilidade dessa mesma razão "não-toda", dividida, quiçá portadora de uma verdade sim, mas parcial e, portanto, 
insuficiente. A face complexa do barroco é confirmada pela variedade de formas com que ele se manifestou em diversos lugares e tempos. Contudo, não obstante a enorme diversidade de barrocos, é inegável a onipresença do traço de uma certa irregularidade da razão que não exclui mais a paixão para sobreviver. A alegria do barroco parece estar na transformação da visão de mundo de um homem que não mais se reconhece como o centro do universo e se põe numa posição de comprometimento com as incertezas do devir e do porvir. O poeta Ferreira Gullar comenta que

No Barroco você tem a impressão de que o mundo está fora do quadro e o pintor apreendeu um pedaço desse espaço, mas o mundo está lá fora. Esta é uma das características da visão barroca ao contrário da visão clássica, da visão renascentista... Essa visão em que o mundo está lá fora, o mundo está fora, o quadro te diz que o mundo está lá fora, esse comprometimento com a realidade é um fator importante para se compreender a visão barroca (1988, p. 220).

E, na medida em que convoca o homem a essa outra visão fora das bordas que delimitam a visibilidade fenomênica -, é que vemos nascer no sujeito olhante a possibilidade de se comprometer com a realidade, com abertura e despojamento típicos de um olhar que se queira utópico. Pois, se o homem barroco não se deixa mais esbarrar na ingenuidade de ver o real como algo controladamente estável e homogeneamente fechado, restar-lhe-á, então, a inquietação desgovernada de um olhar que tenta superar essa angústia ao "criar uma nova fantasia, a fantasia possível dentro de um espaço real que não se pode negar nem, tranqüilamente, assimilar" (1988, p. 224).

O olhar barroco suporta, assim, uma nova fantasia possível que aponta para uma utopia, uma componente de fuga, furtando-se a toda e qualquer forma de expressão dominante, inclusive a que se formaliza sob o primado impositivo de um eu ou de uma razão que se quer plena. No percurso aqui traçado, esperamos ter demonstrado a relação de proximidade entre os olhares do barroco e o da utopia, através da literatura. Atualmente, apesar da sofisticação das formas contemporâneas de manipulação e colonização de um totalitarismo mercadológico globalizado, a América Latina e sua literatura talvez representem, graças à "impureza" dos nossos barrocos, um espaço 
potencializador de devires, pois, como diria Deleuze: "A saúde como literatura, como escrita, consiste em inventar um povo que falta. Compete à função fabuladora inventar um povo. Não se escreve com as próprias lembranças, a menos que delas se faça a origem ou a destinação coletivas de um povo por vir ainda enterrado em suas traições e renegações" (1997, p. 14).

Referências

BOLLE, Willi. Fisionomia da metrópole moderna: representação da história em Walter Benjamin. São Paulo: Edusp, 1994.

CHIAMPI, Irlemar. O realismo maravilhoso. São Paulo: Perspectiva, 1980.

CHIAMPI, Irlemar; AGUIAR, Flávio Wolf (Orgs.). Literatura e história na América Latina. São Paulo: EDUSP, 2001.

CORDIVIOLA, Alfredo (Org.). Um projeto inacabado: identidades latino-americanas no ensaio do século XX. Recife: Bagaço, 2001.

DELEUZE, Gilles. Crítica e clínica. Tradução Peter Pál Pelbart. São Paulo: Ed. 34, 1997.

GRUZINSKI, Serge. Do Barroco ao Neobarroco. Fontes coloniais dos tempos pós-modernos. In: CHIAPPINI, Ligia, AGUIAR, Flávio Wolf (Orgs.). Literatura e hisiória na América Latina. São Paulo: EDUSP, 2001.

GULLAR, Ferreira. Barroco: olhar e vertigem. In: NOVAES, Adauto et al. O olhar. São Paulo: Cia. das Letras, 1988.

KEHL, Maria Rita. Sobre ética e psicanálise. São Paulo: Cia. das Letras, 2002.

PAZ, Francisco Moraes. A poética da história. Curitiba: Ed. UFPR, 1996.

PENA FILHO, Carlos. Os melhores poemas de Carlos Pena Filho. Seleção de Edilberto Coutinho. São Paulo: Global, 2000.

VIEIRA, Antônio. Sermões. Vol. VII. Porto: Lello \& Irmãos, 1945. 